\title{
Physician Reports of Terminal Sedation without Hydration or Nutrition for Patients Nearing Death in the Netherlands
}

Judith A.C. Rietjens, MSc; Agnes van der Heide, MD, PhD; Astrid M. Vrakking, MSc; Bregje D. Onwuteaka-Philipsen, PhD; Paul J. van der Maas, MD, PhD; and Gerrit van der Wal, MD, PhD

Background: Terminal sedation in patients nearing death is an important issue related to end-of-life care.

Objective: To describe the practice of terminal sedation in the Netherlands.

Design: Face-to-face interviews.

Setting: The Netherlands.

Participants: Nationwide stratified sample of 482 physicians; 410 responded and 211 of these reported characteristics of their most recent terminal sedation case.

Measurements: Physician reports of frequency of terminal sedation (defined as the administration of drugs to keep the patient in deep sedation or coma until death, without giving artificial nutrition or hydration), characteristics of the decision-making process, drugs used, the estimated life-shortening effect, and frequency of euthanasia discussions.

Results: Of respondents, $52 \%(95 \% \mathrm{Cl}, 48 \%$ to $57 \%)$ had ever used terminal sedation. Of the $\mathbf{2 1 1}$ most recent cases, physicians used terminal sedation to alleviate severe pain in $51 \%$ of patients
(Cl, $44 \%$ to $58 \%$ ), agitation in $38 \%(\mathrm{Cl}, 32 \%$ to $45 \%)$, and dyspnea in $38 \%(\mathrm{Cl}, 32 \%$ to $45 \%)$. Physicians reported discussing with patients the decision to use deep sedation in $59 \%$ of the 211 most recent cases $(\mathrm{Cl}, 52 \%$ to $66 \%)$ and the decision to forgo artificial nutrition or hydration in $34 \%(\mathrm{Cl}, 28 \%$ to $41 \%)$. Hastening death was partly the intention of the physician in $47 \%$ $(\mathrm{Cl}, 41 \%$ to $54 \%)$ of cases and the explicit intention in $17 \%(\mathrm{Cl}$, $13 \%$ to $22 \%$ ) of cases.

Limitations: The generalizability of physician reports about their most recent cases to all terminal sedation cases is uncertain. In addition, the findings are subject to recall bias and may not apply to other geographic settings.

Conclusions: Terminal sedation precedes a substantial number of deaths in the Netherlands. In about two thirds of most recently reported cases, physicians indicated that in addition to alleviating symptoms, they intended to hasten death.

Ann Intern Med. 2004;141:178-185.

www.annals.org For author affiliations, see end of text.

See editorial comment on pp 236-237.
$\mathbf{P}$ atients nearing death frequently have symptoms such as dyspnea, agitation, pain, and anxiety $(1,2)$. One of the most important goals of the medical care provided to these patients is the alleviation of these symptoms (3). If treatment with analgesic or anxiolytic agents is not effective, sedatives are sometimes used as an alternative to render patients unconscious and then oblivious to their symptoms $(4,5)$. Subsequently, if artificial nutrition and hydration are not given, death will follow soon.

The ethical debate about this practice focuses on the extent to which it should be considered an end-of-life decision that possibly or certainly hastens death. Previous studies have explored the differences and similarities with other end-of-life decisions, such as euthanasia and physician-assisted suicide (6-19). However, little information exists on the medical practice of deep sedation with the forgoing of artificial nutrition or hydration in patients nearing death. Estimates about the frequency of deep sedation at the end of life vary from $15 \%$ to more than $60 \%$, depending on the settings studied and the definitions used (4, 5, 20-26). The terminology used reflects these differences in definition of the practice of deep sedation at the end of life. Although "terminal sedation" is the most commonly used term, other frequently used terms, which demonstrate the different perspectives from which this practice is viewed, are "sedation for intractable distress in the im- minently dying," "palliative sedation therapy," "slow euthanasia," "opioid coma," or "anesthetic coma" (6, 27-30).

The present study describes the practice of terminal sedation in the Netherlands. This study was part of the evaluation of the notification procedure for physicianassisted death in the Netherlands, which was commissioned by the ministers of Health and Justice (31).

\section{Methods}

\section{Respondent Characteristics}

We interviewed a nationwide sample of 410 physicians: 208 clinical specialists, 125 general practitioners, and 77 nursing home physicians. In the Netherlands, clinical specialists provide hospital care, general practitioners provide nonspecialized care outside the hospital, and nursing home physicians work in long-term care institutions mainly for elderly people. The proportions of deaths in these health care settings are approximately 35\%, 42\%, and $23 \%$, respectively. The specialties involved in our study covered about $95 \%$ of all deaths in the Netherlands in 2001. The respondents were selected according to the following criteria: They were required to be in active practice at the time of the interview and to have actively practiced medicine within the registered specialty for the past 2 years in the same setting. All addresses were taken from the professional registries of the relevant specialties. To arrive 
at the desired number of 410 physicians, we sampled 482 physicians. Seventy-two physicians (15\%) declined to take part in the study: $17 \%$ of clinical specialists, $18 \%$ of general practitioners, and $3 \%$ of nursing home physicians. Nonresponders did not differ in age from responders.

Face-to-face interviews were conducted by experienced part-time working or recently retired physicians who were trained to administer the structured questionnaires. All interviews took place between March 2002 and October 2002. We applied strict rules to ensure the anonymity of all physicians and patients studied.

\section{Interview Process}

The interview schedule addressed experiences with end-of-life decision making (Appendix Figure [Questionnaire on Terminal Sedation], available at www.annals.org). Terminal sedation was defined as the administration of drugs to keep the patient in deep sedation or coma until death, without giving artificial nutrition or hydration. The respondents were first asked whether they had ever used terminal sedation and, subsequently, how often they had performed this practice in 2000 and 2001. Additional questions about the practice of terminal sedation concerned the physician's most recent patient to have received terminal sedation $(n=211)$. The physicians were asked about the patient's characteristics; whether or not sedation or the forgoing of artificial nutrition or hydration had been discussed with the patient, family, or other health care professionals; the drugs used; the intention of the physician; the estimated life-shortening effect; and whether euthanasia was discussed during the decision process.

\section{Statistical Analysis}

We calculated all estimates about the occurrence of terminal sedation in the Netherlands by weighting the estimates of individual physicians. Weighting factors were based on differences in sampling fractions and response rates for the different specialties. These sampling fractions were 125 of 7027 for general practitioners, 77 of 810 for nursing home physicians, 34 of 394 for cardiologists, 34 of 545 for neurologists, 69 of 1321 for specialists in internal medicine, 35 of 325 for pulmonologists, and 36 of 769 for surgeons. The probabilities used to determine sampling weights were 1 in 56 for general practitioners, 1 in 11 for nursing home physicians, 1 in 12 for cardiologists, 1 in 16 for neurologists, 1 in 19 for specialists in internal medicine, 1 in 9 for pulmonologists, and 1 in 21 for surgeons.

Data on the 211 most recent patients seen by physicians were not weighted. All analyses were done by using SPSS software, version 10.0 (SPSS, Inc., Chicago, Illinois).

\section{Role of the Funding Sources}

The sponsors approved the study design but were not involved in the collection, analysis, or interpretation of the data or in the decision to submit the manuscript for publication.

\section{Context}

Terminal sedation, the administration of sedating medications with cessation of nutrition and hydration, is an option for care of patients who are nearing death. However, little is known about physician's experience with terminal sedation.

\section{Contribution}

Of more than 400 physicians in the Netherlands who completed a survey about end-of-life care, just over half had ever used terminal sedation. Common reasons for using terminal sedation were relief of pain, agitation, or dyspnea. Hastening death was the primary intention in only $17 \%$ of reported cases.

\section{Caution}

Because attitudes and practices regarding terminal sedation vary geographically and culturally, it is unclear whether these results are generalizable outside of the Netherlands.

-The Editors

\section{RESULTS}

Most of the 410 physicians interviewed (76\%) were men; $51 \%$ were clinical specialists, $30 \%$ were general practitioners, and 19\% were nursing home physicians (Tables 1 and 2). Of all physicians, a weighted percentage of 52\% (95\% CI, $48 \%$ to $57 \%$ ) had ever practiced terminal sedation. This percentage was $55 \%$ (CI, $49 \%$ to $62 \%$ ) for clinical specialists, $48 \%$ (CI, 39\% to $57 \%$ ) for general practitioners, and $75 \%$ (CI, 64\% to $83 \%$ ) for nursing home physicians. We asked all interviewed physicians to estimate the total number of times they performed terminal sedation in 2000 and 2001. These numbers were extrapolated to the total number of 140377 deaths in 2001 by multiplying them with the weighting factor for each specialty and assuming that the numbers were similar for the $5 \%$ of deaths covered by hospital doctors from specialties other than the ones included in our study. This extrap-

Table 1. Characteristics of Interviewed Physicians

\begin{tabular}{|c|c|}
\hline Variable & $\begin{array}{l}\text { Physicians } \\
(n=410), \%\end{array}$ \\
\hline \multicolumn{2}{|l|}{ Sex } \\
\hline Male & 76 \\
\hline Female & 24 \\
\hline \multicolumn{2}{|l|}{ Age } \\
\hline $30-44$ y & 35 \\
\hline $45-54$ y & 45 \\
\hline$\geq 55$ y & 20 \\
\hline \multicolumn{2}{|l|}{ Specialty } \\
\hline Clinical specialist & 51 \\
\hline General practitioner & 30 \\
\hline Nursing home physician & 19 \\
\hline
\end{tabular}

3 August 2004 $\mid$ Annals of Internal Medicine $\mid$ Volume $141 \bullet$ Number $3 \mid 179$ 
ARTICLE Terminal Sedation in the Netherlands

Table 2. Proportion of Deaths per Specialty*

\begin{tabular}{|c|c|}
\hline Specialty & $\begin{array}{l}\text { Deaths } \\
(n=140377), \%\end{array}$ \\
\hline Clinical specialist & 35 \\
\hline General practitioner & 42 \\
\hline Nursing home physician & 23 \\
\hline
\end{tabular}

* From Statistics Netherlands; Central Death Registry 2001 (32).

olation suggests that physicians used terminal sedation in $10.0 \%$ (CI, $9.1 \%$ to $10.8 \%$ ) of all deaths in that year. Of the $10.0 \%$ of deaths preceded by terminal sedation, $5.5 \%$ (CI, $5.0 \%$ to $6.1 \%$ ) were attended by clinical specialists, $2.5 \%$ (CI, $1.9 \%$ to $3.2 \%$ ) by general practitioners, and $2.0 \%$ (CI, $1.7 \%$ to $2.2 \%$ ) by nursing home physicians.

Of all physicians who had ever used terminal sedation, 211 provided information about their most recent cases of terminal sedation (103 clinical specialists, 53 general practitioners, and 55 nursing home physicians). Of these most recent cases, $78 \%$ (CI, $72 \%$ to $83 \%$ ) involved patients 65 years of age or older and $54 \%$ (CI, $47 \%$ to $60 \%$ ) involved patients who had cancer (Table 3). Clinical specialists and nursing home physicians also frequently reported practicing terminal sedation in patients with cardiovascular diseases. The most frequently mentioned reasons for using terminal sedation were the alleviation of pain $(51 \%$ [CI, $44 \%$ to $58 \%$ ]), agitation (38\% [CI, $32 \%$ to $45 \%]$ ), dyspnea $(38 \%$ [CI, $32 \%$ to $45 \%])$, and anxiety (11\% [CI, $8 \%$ to $16 \%])$.

In $59 \%$ (CI, $52 \%$ to $66 \%$ ) of the most recent cases seen by physicians, the physician had discussed the sedation with the patient (Table 4); in 33\% (CI, 27\% to 39\%) of the cases, the patient had requested deep sedation. The main reasons for not discussing deep sedation with the patient were the fact that the patient was incompetent or subcomatose (25\% [CI, $20 \%$ to $31 \%])$. The decision to forgo artificial nutrition or hydration was discussed less frequently with the patient; the respondents reported discussing this topic in $34 \%$ (CI, $28 \%$ to $41 \%$ ) of their most recent cases and receiving a request from the patient to forgo artificial nutrition or hydration in $9 \%$ (CI, $6 \%$ to $13 \%)$. Next to patient incompetence (37\% [CI, 31\% to $44 \%]$ ), another frequently mentioned reason for not discussing the decision to forgo artificial nutrition or hydration was that many physicians perceived this not as optional but rather as a given; they considered terminal sedation to preclude the concomitant use of artificial nutrition and hydration (23\% [CI, $18 \%$ to $29 \%]$ ) (data not shown).

The decision to use sedation was discussed with relatives of the patient in $93 \%$ (CI, $89 \%$ to $96 \%$ ) of the most recent cases seen by physicians, and the decision to forgo artificial nutrition or hydration was discussed with relatives in $73 \%$ (CI, $67 \%$ to $79 \%$ ) of the most recent cases. The physicians had discussed the sedation with other caregivers in $79 \%(\mathrm{CI}, 73 \%$ to $84 \%)$ of cases and had discussed forgoing artificial nutrition or hydration in $67 \%$ (CI, 60\% to $73 \%$ ) of cases. Clinical specialists, nursing home physicians, and general practitioners discussed the sedation with other physicians in $76 \%(\mathrm{CI}, 67 \%$ to $83 \%), 38 \%$ (CI, $26 \%$ to $52 \%$ ), and $29 \%$ (CI, $18 \%$ to $42 \%$ ) of their most recent cases, respectively. Nurses were often involved in the decision making by clinical specialists and nursing home physicians. Specialists in palliative care from other institutions were rarely consulted. In $17 \%$ (CI, $12 \%$ to $22 \%$ ) of the physicians' most recent cases, neither the sedation nor the forgoing of artificial nutrition or hydration was discussed with other caregivers, and in $1 \%$ (CI, $0 \%$ to $4 \%$ ) of the cases, these decisions were not discussed with the patient, the relatives, or other caregivers (data not shown).

Most physicians recalled having administered benzodiazepines in their most recent cases of terminal sedation. Twenty-one percent (CI, $16 \%$ to $27 \%$ ) of physicians used only these drugs; $35 \%$ (CI, $29 \%$ to $42 \%$ ) combined benzodiazepines with morphine, and $4 \%$ (CI, $2 \%$ to $8 \%$ ) combined benzodiazepines with another drug (Table 5). In the remaining cases, physicians mostly used morphine. No physicians used barbiturates. General practitioners and nursing home physicians reported using benzodiazepines relatively frequently, which is in contrast to the clinical specialists, who were more likely to administer morphine only.

Of all physicians, $36 \%$ (CI, $29 \%$ to $42 \%$ ) reported having made their most recent decision to perform terminal sedation without the intention of hastening death. The

Table 3. Characteristics of the Sample Consisting of Each Physician's Most Recent Case of Terminal Sedation*

\begin{tabular}{|c|c|c|}
\hline Variable & $\begin{array}{l}\text { Sample Consisting } \\
\text { of Physician's Most } \\
\text { Recent Case } \\
(n=211), n(\%)\end{array}$ & $\begin{array}{l}\text { All Deaths in } \\
\text { the Netherlands } \\
\text { in } 2001, \%\end{array}$ \\
\hline \multicolumn{3}{|l|}{ Sex } \\
\hline Male & 99 (47) & 49 \\
\hline Female & $112(53)$ & 51 \\
\hline \multicolumn{3}{|l|}{ Age† } \\
\hline $0-64$ y & $46(22)$ & 20 \\
\hline $65-79$ y & $88(42)$ & 35 \\
\hline$\geq 80 y$ & $76(36)$ & 46 \\
\hline \multicolumn{3}{|l|}{ Main diagnosis } \\
\hline Cancer & $113(54)$ & 27 \\
\hline Cardiovascular diseases & $51(24)$ & 25 \\
\hline Pulmonary diseases & $14(7)$ & 10 \\
\hline Nervous system diseases & $17(8)$ & 11 \\
\hline Other & $16(8)$ & 27 \\
\hline \multicolumn{3}{|l|}{ Reason for deep sedation $\neq$} \\
\hline Pain & $108(51)$ & NA \\
\hline Agitation & $80(38)$ & NA \\
\hline Dyspnea & $80(38)$ & NA \\
\hline Anxiety & $24(11)$ & NA \\
\hline Other & $62(29)$ & NA \\
\hline
\end{tabular}

* NA $=$ not available.

† In 1 case, information on age was missing.

‡ One or more answers are possible. 
Terminal Sedation in the Netherlands ARTICLE

Table 4. Discussion about Deep Sedation and Forgoing Artificial Nutrition or Hydration in Each Physician's Most Recent Case of Terminal Sedation, by Physician Specialty

\begin{tabular}{|c|c|c|c|c|}
\hline Topic of Discussion & $\begin{array}{l}\text { Cases Seen by Clinical } \\
\text { Specialists }(n=103) \text {, } \\
n(\%)\end{array}$ & $\begin{array}{l}\text { Cases Seen by General } \\
\text { Practitioners }(n=53) \text {, } \\
n(\%)\end{array}$ & $\begin{array}{l}\text { Cases Seen by Nursing } \\
\text { Home Physicians }(n=55) \text {, } \\
n(\%)\end{array}$ & $\begin{array}{l}\text { Cases Seen by All } \\
\text { Physicians }(n=211) \text {, } \\
n(\%)\end{array}$ \\
\hline \multicolumn{5}{|l|}{ Deep sedation } \\
\hline Discussed with patient & $67(65)$ & $28(53)$ & $30(55)$ & $125(59)$ \\
\hline \multicolumn{5}{|l|}{ Reason for not discussing* } \\
\hline Patient was incompetent or subcomatose & $27(26)$ & $13(25)$ & $13(24)$ & $53(25)$ \\
\hline $\begin{array}{l}\text { Deep sedation was clearly in the best } \\
\text { interest of the patient }\end{array}$ & $4(4)$ & $4(8)$ & $6(11)$ & $14(7)$ \\
\hline Patient had dementia & $2(2)$ & $1(2)$ & $12(22)$ & $15(7)$ \\
\hline $\begin{array}{l}\text { Discussion would have done more harm } \\
\text { than good }\end{array}$ & $0(0)$ & $1(2)$ & $1(2)$ & $2(1)$ \\
\hline Other reason & $5(5)$ & $5(9)$ & $3(5)$ & $13(6)$ \\
\hline Discussed with relativest & $94(91)$ & $48(92)$ & $53(96)$ & $195(93)$ \\
\hline Discussed with other caregivers* + & $91(88)$ & $30(57)$ & $46(84)$ & $167(79)$ \\
\hline Another physician & $78(76)$ & $15(29)$ & $21(38)$ & $114(54)$ \\
\hline Nurses & $70(68)$ & $14(27)$ & $41(75)$ & $125(60)$ \\
\hline $\begin{array}{l}\text { Specialists in palliative care from other } \\
\text { institutions }\end{array}$ & $3(3)$ & $5(10)$ & $0(0)$ & $8(4)$ \\
\hline Multidisciplinary pain management team & $8(8)$ & $2(4)$ & $0(0)$ & $10(5)$ \\
\hline Other & $4(4)$ & $6(12)$ & $4(7)$ & $14(7)$ \\
\hline \multicolumn{5}{|l|}{ Forgoing artificial nutrition or hydration } \\
\hline Discussed with patient‡ & $33(33)$ & $14(27)$ & $23(43)$ & $70(34)$ \\
\hline Requested by patient $¥$ & $9(9)$ & $3(6)$ & $6(11)$ & $18(9)$ \\
\hline Discussed with relatives $¥$ & $68(67)$ & $34(65)$ & $49(91)$ & $151(73)$ \\
\hline Discussed with other caregivers* $\S$ & $76(75)$ & $20(38)$ & $43(80)$ & $139(67)$ \\
\hline Another physician & $58(57)$ & $10(19)$ & $14(26)$ & $82(39)$ \\
\hline Nurses & $60(59)$ & $11(21)$ & $41(76)$ & $112(54)$ \\
\hline $\begin{array}{l}\text { Specialists in palliative care from other } \\
\text { institutions }\end{array}$ & $3(3)$ & $1(2)$ & $0(0)$ & $4(2)$ \\
\hline Multidisciplinary pain management team & $4(4)$ & $1(2)$ & $0(0)$ & $5(2)$ \\
\hline Other & $1(1)$ & $4(8)$ & $4(7)$ & $9(4)$ \\
\hline
\end{tabular}

* One or more answers are possible.

† In 1 case, information was missing.

‡ In 4 cases, information was missing.

$\S$ In 3 cases, information was missing.

physicians partly had the intention to hasten death in $47 \%$ (CI, $41 \%$ to $54 \%$ ) of cases and had the explicit intention to hasten death in $17 \%(\mathrm{CI}, 13 \%$ to $22 \%$ ) of cases. This explicit intention involved only the sedation in $2 \%$ (CI, $1 \%$ to $5 \%$ ) of the physicians' most recent cases, only the forgoing of artificial nutrition or hydration in 14\% (CI, $10 \%$ to $19 \%$ ) of cases, and both sedation and the forgoing of artificial nutrition or hydration in $1 \%$ (CI, $0 \%$ to $4 \%$ ) of cases.

Of the physicians reporting a recent case, $40 \%$ (CI, $34 \%$ to $45 \%$ ) estimated that the patient's life had been shortened by 24 hours or less. In $27 \%$ (CI, $21 \%$ to $33 \%$ ) of the cases, life was estimated to have been shortened by more than 1 week.

Thirty-seven percent (CI, 30\% to 43\%) of physicians discussed the option of euthanasia with the patient during the decision-making process. The main reasons for deciding against euthanasia were as follows: The patient preferred terminal sedation ( $9 \%$ [CI, $5 \%$ to $14 \%]$ ); the patient did not explicitly request euthanasia $(8 \%$ [CI, $5 \%$ to $12 \%]$ ); and the patient viewed terminal sedation as less disturbing to the natural process of dying than euthanasia (4\% [CI, $2 \%$ to $8 \%]$ ).

\section{Discussion}

Terminal sedation is frequently used in end-of-life care in the Netherlands. Half of all physicians have practiced terminal sedation. Our study shows that terminal sedation preceded an estimated $10 \%$ (CI, 9\% to $11 \%$ ) of all deaths in the Netherlands. Another recent Dutch study with a different study design estimated the incidence of terminal sedation to be $4 \%$ of all deaths (31). These percentages are lower than the previously reported percentages of $15 \%$ to $60 \%(4,5,20-24,26)$. This difference is probably explained in part by the fact that the incidences found in most other studies do not refer to all deaths in a population but rather to deaths in a selected inpatient care setting, such as a hospital or a hospice $(4,5,20,22-25)$. Another factor that may explain the higher rates of terminal sedation in other studies is our very specific definition of terminal sedation: Patients had to be deeply sedated or comatose, and 
ARTICLE $\mid$ Terminal Sedation in the Netherlands

Table 5. Drugs Used, Intention of the Physician, Estimated Shortening of Life, and Discussion about Euthanasia in Each Physician's Most Recent Case of Terminal Sedation, by Physician Specialty

\begin{tabular}{|c|c|c|c|c|}
\hline Variable & $\begin{array}{l}\text { Clinical Specialists } \\
(n=103), n(\%)\end{array}$ & $\begin{array}{l}\text { General Practitioners } \\
(n=53), n(\%)\end{array}$ & $\begin{array}{l}\text { Nursing Home Physicians } \\
(n=55), n(\%)\end{array}$ & $\begin{array}{l}\text { All Physicians } \\
(n=211), n(\%)\end{array}$ \\
\hline \multicolumn{5}{|l|}{ Drugs used* } \\
\hline Only benzodiazepines & $12(12)$ & $14(26)$ & $19(35)$ & $45(21)$ \\
\hline $\begin{array}{l}\text { Benzodiazepines in combination with } \\
\text { morphine or morphine } \\
\text { derivativest }\end{array}$ & $35(34)$ & $17(32)$ & $22(40)$ & $74(35)$ \\
\hline $\begin{array}{l}\text { Benzodiazepines in combination with } \\
\text { other drugs (excluding morphine } \\
\text { or morphine derivatives) }\end{array}$ & $2(2)$ & $7(13)$ & $0(0)$ & $9(4)$ \\
\hline $\begin{array}{l}\text { Only morphine or morphine } \\
\text { derivatives }\end{array}$ & $44(43)$ & $10(19)$ & $12(22)$ & $66(31)$ \\
\hline $\begin{array}{l}\text { Morphine or morphine derivatives in } \\
\text { combination with other drugs } \\
\text { (excluding benzodiazepines) }\end{array}$ & $4(4)$ & $4(8)$ & $2(4)$ & $10(5)$ \\
\hline All other drugs or combinations & $5(5)$ & $1(2)$ & $0(0)$ & $6(3)$ \\
\hline \multicolumn{5}{|l|}{ Terminal sedation used $\neq$} \\
\hline $\begin{array}{l}\text { Without the intention of hastening } \\
\text { death§ }\end{array}$ & $35(34)$ & $17(32)$ & $23(42)$ & $75(36)$ \\
\hline $\begin{array}{l}\text { Partly with the intention of } \\
\text { hastening death§ }\end{array}$ & $51(50)$ & $25(47)$ & $24(44)$ & $100(47)$ \\
\hline $\begin{array}{l}\text { With the explicit intention of } \\
\text { hastening death§ }\end{array}$ & $17(17)$ & $11(21)$ & $8(15)$ & $36(17)$ \\
\hline \multicolumn{5}{|l|}{ Explicit intention concerned§ } \\
\hline Sedation & $3(3)$ & $1(2)$ & $0(0)$ & $4(2)$ \\
\hline $\begin{array}{l}\text { Forgoing artificial nutrition or } \\
\text { hydration }\end{array}$ & $14(14)$ & $7(13)$ & $8(15)$ & $29(14)$ \\
\hline $\begin{array}{l}\text { Both sedation and forgoing } \\
\text { artificial nutrition or hydration }\end{array}$ & $0(0)$ & $3(6)$ & $0(0)$ & $3(1)$ \\
\hline \multicolumn{5}{|l|}{ Estimated shortening of life $\|$} \\
\hline No shortening or $<24 \mathrm{~h}$ & $36(36)$ & $23(44)$ & $22(42)$ & $81(40)$ \\
\hline $1-7 d$ & $40(40)$ & $16(31)$ & $11(21)$ & $67(33)$ \\
\hline $1-4$ wk & 19 (19) & $11(21)$ & $14(27)$ & $44(21)$ \\
\hline$>1 \mathrm{mo}$ & $6(6)$ & $2(4)$ & $5(10)$ & $13(6)$ \\
\hline Euthanasia discussedף & $26(25)$ & $35(66)$ & $16(29)$ & $77(37)$ \\
\hline \multicolumn{5}{|l|}{$\begin{array}{l}\text { Reasons euthanasia was not } \\
\text { performed }\end{array}$} \\
\hline Wish of the patient & $4(4)$ & $11(21)$ & $4(7)$ & $19(9)$ \\
\hline No explicit patient request & $5(5)$ & $8(15)$ & $3(5)$ & $16(8)$ \\
\hline $\begin{array}{c}\text { Terminal sedation is palliative care, } \\
\text { part of natural process of dying }\end{array}$ & $6(6)$ & $3(6)$ & $0(0)$ & $9(4)$ \\
\hline No legal framework & $3(3)$ & $3(6)$ & $0(0)$ & $6(3)$ \\
\hline Rapid dying process & $1(1)$ & $3(6)$ & $2(4)$ & $6(3)$ \\
\hline Unknown/other & $8(8)$ & $7(13)$ & $7(13)$ & $22(10)$ \\
\hline
\end{tabular}

* In 1 case, information on drugs used was missing.

† Possibly combined with other drugs.

† Forgoing artificial nutrition or hydration concerned the intention of "hastening death" or "not to prolong life."

$\S$ Intention concerned either sedation or forgoing artificial nutrition or hydration.

\| In 6 cases, information on estimated shortening of life was missing.

I In 1 case, information on whether euthanasia was discussed was missing.

patients receiving artificial nutrition and hydration were excluded. Other studies used less restrictive definitions. Some included moderately sedated patients, some included a majority of patients who were sedated intermittently, and none excluded patients receiving artificial nutrition and hydration (4, 5, 20-24, 26).

Clinical specialists performed half of all cases of terminal sedation, although they attended $35 \%$ of the total number of deaths in the Netherlands. Apparently, terminal sedation is more often practiced in a hospital than at home. This may be explained in part by the fact that in-hospital

$182 \mid 3$ August 2004 Annals of Internal Medicine $\mid$ Volume $141 \cdot$ Number 3 patients (especially those with cancer or cardiovascular disease) more often have severe symptoms or extreme exacerbations of conditions.

The sample of physicians' most recent cases of terminal sedation included about equal proportions of both sexes. Approximately one third of all deaths resulting from terminal sedation were in patients 80 years of age or older, whereas $46 \%$ of all deaths in the general population occurred in this age group (33). The major reasons for using terminal sedation were to alleviate severe pain, agitation, dyspnea, and anxiety. In a review of 17 studies that ad- 
dressed the use of sedatives in the care of patients with cancer who were in the final stages of life, a syndrome of delirium and agitation was the most frequently mentioned indication for sedative use; pain was a much less common reason for sedation (21). However, most of these studies did not take into account the use of opioids. In addition, patients in some of these studies were only moderately sedated.

In our study, terminal sedation was performed with benzodiazepines in $60 \%$ of the most recent cases seen by physicians and with morphine or morphine derivatives in the remaining most recent cases seen. Other studies also found that benzodiazepines were most commonly used for deep sedation in patients nearing death. The use of opioids alone for deep sedation is regarded as less effective than the use of sedatives and may even be counterproductive $(8,21$, 22). Cherny and Portenoy have produced guidelines for the use of sedation for controlling symptoms; in their opinion, benzodiazepines are the most favored class of sedatives in palliative care worldwide (34). Some researchers suggest that opioid use for relief of pain and other symptoms should be continued when sedation is being instituted to avoid the possibility of unobservable pain or symptoms of opioid withdrawal (8). Opioids are frequently used in hospital settings to treat pain and other symptoms. The relatively high proportion of morphine-induced cases of terminal sedation in our study may indicate that unconsciousness was a consequence of pain and symptom management or of progression of the underlying disease.

In our study, terminal sedation was almost always discussed with relatives but not always with the patient, who was often no longer communicative. A remarkable finding was that general practitioners were much less likely to consult other physicians or caregivers. In addition, the physicians in our study rarely consulted specialists in palliative care from other institutions and rarely consulted pain management teams. General practitioners were less likely to involve nurses in decision making about terminal sedation than were other physicians. This may reflect the fact that nurses are less available to general practitioners than to physicians working in institutional settings.

If life-sustaining treatment, such as artificial nutrition or hydration, is forgone in patients nearing death, death will usually occur within a short time. However, in our study, 36\% (CI, 29\% to 42\%) of the physicians made their most recent decision to perform terminal sedation without the intention of hastening death. The physicians partly had the intention to hasten death in $47 \%$ (CI, $41 \%$ to $54 \%$ ) of cases and the explicit intention to hasten death in $17 \%$ (CI, $13 \%$ to $22 \%$ ) of cases. In most reported cases, this explicit intention concerned the decision not to give artificial nutrition or hydration. The estimated shortening of life was limited to less than 1 week in $73 \%$ (CI, $67 \%$ to $79 \%$ ) of the cases most recently seen by physicians, indicating that the practice of terminal sedation is not restricted to patients for whom death was imminent.
When making the decision to perform terminal sedation, the physician may have considered euthanasia, that is, the administration of drugs with the explicit intention to end life at the patient's request. The Dutch euthanasia law was enacted in 2002, but from the early 1990s, physicians who met the official criteria for prudent practice were not prosecuted for performing euthanasia. Euthanasia was discussed in the course of the decision-making process in about $40 \%$ of the cases. Physicians reported that the main reasons for choosing terminal sedation rather than euthanasia were the patient's preference for terminal sedation to euthanasia and the patient's belief that terminal sedation was less intrusive than euthanasia on the natural dying process. In some cases, the physicians reported that euthanasia could not be performed because the patient did not fulfill the requirements (for example, an explicit patient request for euthanasia) of prudent practice for euthanasia. In general, there was a lack of explicit request when the patient was incompetent or moribund.

In the Dutch context, there are some obvious ethical and practical differences between terminal sedation and euthanasia. By definition, euthanasia is the result of an explicit request of the patient. Such a request is not necessary for terminal sedation. However, the presence $(33 \%$ in our study) or absence of a patient's request or at least discussion with the patient (59\% in our study) can be important in the justification of terminal sedation. With euthanasia, patients die as a result of the administration of lethal drugs. By contrast, with terminal sedation, patients die naturally as a result of their disease (this is most likely when death occurs in a few days), as a result of forgoing artificial nutrition or hydration (when death occurs after more than a few days), or as a result of the administration of sedatives. In addition, physicians always use euthanasia with the explicit intention of hastening death, whereas hastening death is the primary intent in only a fraction of terminal sedation cases. Researchers have shown that approximately $2.6 \%$ of all deaths in the Netherlands are preceded by euthanasia; $20 \%$ are preceded by the alleviation of pain or symptoms; and $20 \%$ are preceded by decisions to withhold or withdraw potentially life-prolonging treatments (33). Cases of terminal sedation in which hastening of death was not intended or taken into account cannot be considered to represent either of these end-of-life decisions. When physicians prescribe sedatives with the explicit intention of hastening death, their actions may be regarded as intentional ending of life.

Our study has several limitations. First, face-to-face interviews may be biased by interviewer interpretation. Moreover, the respondents may have felt obligated to give socially acceptable answers. We attempted to eliminate these biases by carefully selecting and training the interviewers and by ensuring strict anonymity of the respondents. Second, the respondents may have had difficulty recalling the patient's characteristics; however, recall bias was probably limited because most cases involved patients

3 August 2004 Annals of Internal Medicine $\mid$ Volume 141 • Number $3 \mid \mathbf{1 8 3}$ 
who died during the preceding 2 years. Third, the term "terminal sedation" can evoke different connotations and interpretations in respondents. We tried to avoid this problem by providing a very specific definition of the term. Last, our findings may not be generalizable to other countries because of the openness in Dutch society about endof-life issues.

We conclude that terminal sedation precedes a substantial number of deaths in the Netherlands. Terminal sedation is an option that is used to alleviate severe symptoms in the last phase of life; in most cases, it shortens life to less than 1 week. According to our reports about physicians' most recent cases, terminal sedation is usually provided after discussion with the patient, relatives, and caregivers. In a limited number of cases, when the physician administers a sedative with the explicit intention to hasten death at the explicit request of the patient, terminal sedation seems to approximate the practice of euthanasia.

From Erasmus MC, Rotterdam, and Vrije Universiteit Medical Center, Amsterdam, the Netherlands.

Acknowledgments: The authors thank the members of the Steering Committee for their continuous support throughout the study; the physicians who provided the study data; the interviewers; Caspar W.N. Looman for his statistical support and advice; Karen L. Gribling for translation advice; and the chairman of the Royal Dutch Medical Association and the Chief Inspector for Health Care for their support for the study.

Grant Support: By a grant from the Ministry of Health and the Ministry of Justice.

Potential Financial Conflicts of Interest: None disclosed.

Requests for Single Reprints: Judith Rietjens, MSc, Department of Public Health, Erasmus MC, PO Box 1738, 3000 DR Rotterdam, the Netherlands; e-mail, j.rietjens@erasmusmc.nl.

Current author addresses and author contributions are available at www .annals.org.

\section{References}

1. Vainio A, Auvinen A. Prevalence of symptoms among patients with advanced cancer: an international collaborative study. Symptom Prevalence Group. J Pain Symptom Manage. 1996;12:3-10. [PMID: 8718910]

2. Coyle N, Adelhardt J, Foley KM, Portenoy RK. Character of terminal illness in the advanced cancer patient: pain and other symptoms during the last four weeks of life. J Pain Symptom Manage. 1990;5:83-93. [PMID: 2348092]

3. Sepulveda C, Marlin A, Yoshida T, Ullrich A. Palliative Care: the World Health Organization's global perspective. J Pain Symptom Manage. 2002;24: 91-6. [PMID: 12231124]

4. Ventafridda V, Ripamonti C, De Conno F, Tamburini M, Cassileth BR. Symptom prevalence and control during cancer patients' last days of life. J Palliat Care. 1990;6:7-11. [PMID: 1700099]

5. Fainsinger RL, Waller A, Bercovici M, Bengtson K, Landman W, Hosking $\mathrm{M}$, et al. A multicentre international study of sedation for uncontrolled symptoms in terminally ill patients. Palliat Med. 2000;14:257-65. [PMID: 10974977] 6. Billings JA, Block SD. Slow euthanasia. J Palliat Care. 1996;12:21-30. [PMID: 9019033]

184 3 August $2004 \mid$ Annals of Internal Medicine $\mid$ Volume $141 \bullet$ Number 3
7. Quill TE, Lo B, Brock DW. Palliative options of last resort: a comparison of voluntarily stopping eating and drinking, terminal sedation, physician-assisted suicide, and voluntary active euthanasia. JAMA. 1997;278:2099-104. [PMID: 9403426]

8. Quill TE, Byock IR. Responding to intractable terminal suffering: the role of terminal sedation and voluntary refusal of food and fluids. ACP-ASIM End-ofLife Care Consensus Panel. American College of Physicians-American Society of Internal Medicine. Ann Intern Med. 2000;132:408-14. [PMID: 10691593]

9. Letvak R. Palliative options at the end of life [Letter]. JAMA. 1998;279:1065; author reply 1066-7. [PMID: 9546556]

10. Sulmasy DP, Ury WA, Ahronheim JC, Siegler M, Kass L, Lantos J, et al. Responding to intractable terminal suffering [Letter]. Ann Intern Med. 2000; 133:560-2; disc 561-2. [PMID: 11015175]

11. Sulmasy DP, Ury WA, Ahronheim JC, Siegler M, Kass L, Lantos J, et al. Palliative treatment of last resort and assisted suicide [Letter]. Ann Intern Med. 2000;133:562-3. [PMID: 11015177]

12. Loewy EH. Terminal sedation, self-starvation, and orchestrating the end of life. Arch Intern Med. 2001;161:329-32. [PMID: 11176757]

13. Jansen LA, Sulmasy DP. Sedation, alimentation, hydration, and equivocation: careful conversation about care at the end of life. Ann Intern Med. 2002; 136:845-9. [PMID: 12044133]

14. Quill TE, Lee BC, Nunn S. Palliative treatments of last resort: choosing the least harmful alternative. University of Pennsylvania Center for Bioethics Assisted Suicide Consensus Panel. Ann Intern Med. 2000;132:488-93. [PMID: 10733450]

15. Sasser CG. Careful conversation about care at the end of life [Letter]. Ann Intern Med. 2002;137:1008-10; author reply 1008-10. [PMID: 12484724]

16. Rousseau P. Careful conversation about care at the end of life [Letter]. Ann Intern Med. 2002;137:1008-10; author reply 1008-10. [PMID: 12484729]

17. Quill TE. Careful conversation about care at the end of life [Letter]. Ann Intern Med. 2002;137:1008-10; author reply 1008-10. [PMID: 12484728]

18. Morita T, Tsuneto S, Shima Y. Careful conversation about care at the end of life [Letter]. Ann Intern Med. 2002;137:W1; author reply W1. [PMID: 12484744]

19. Kvasnicka JH. Careful conversation about care at the end of life [Letter]. Ann Intern Med. 2002;137:W2; author reply W2. [PMID: 12484745]

20. Stone P, Phillips C, Spruyt O, Waight C. A comparison of the use of sedatives in a hospital support team and in a hospice. Palliat Med. 1997;11: 140-4. [PMID: 9156110]

21. Sykes N, Thorns A. The use of opioids and sedatives at the end of life. Lancet Oncol. 2003;4:312-8. [PMID: 12732169]

22. Fainsinger RL, Landman W, Hoskings M, Bruera E. Sedation for uncontrolled symptoms in a South African hospice. J Pain Symptom Manage. 1998; 16:145-52. [PMID: 9769616]

23. Chiu TY, Hu WY, Lue BH, Cheng SY, Chen CY. Sedation for refractory symptoms of terminal cancer patients in Taiwan. J Pain Symptom Manage. 2001;21:467-72. [PMID: 11397604]

24. Muller-Busch HC, Andres I, Jehser T. Sedation in palliative care-a critical analysis of 7 years experience. BMC Palliat Care. 2003;2:2. [PMID: 12744722] 25. Sykes N, Thorns A. Sedative use in the last week of life and the implications for end-of-life decision making. Arch Intern Med. 2003;163:341-4. [PMID: 12578515]

26. Morita T, Akechi T, Sugawara Y, Chihara S, Uchitomi Y. Practices and attitudes of Japanese oncologists and palliative care physicians concerning terminal sedation: a nationwide survey. J Clin Oncol. 2002;20:758-64. [PMID: 11821458]

27. Chater S, Viola R, Paterson J, Jarvis V. Sedation for intractable distress in the dying—a survey of experts. Palliat Med. 1998;12:255-69. [PMID: 9743824]

28. Morita T, Hirai K, Akechi T, Uchitomi Y. Similarity and difference among standard medical care, palliative sedation therapy, and euthanasia: a multidimensional scaling analysis on physicians' and the general population's opinions. J Pain Symptom Manage. 2003;25:357-62. [PMID: 12691687]

29. Emanuel LL. Facing requests for physician-assisted suicide: toward a practical and principled clinical skill set. JAMA. 1998;280:643-7. [PMID: 9718058]

30. Morita T, Tsuneto S, Shima Y. Proposed definitions for terminal sedation [Letter]. Lancet. 2001;358:335-6. [PMID: 11501540] 
31. van der Wal G, van der Heide A, Onwuteaka-Philipsen BD, van der Maas PJ. Medische besluitvorming aan het einde van het leven. De praktijk en de toetsingsprocedure euthanasie. (Medical decision-making at the end of life. Practice and notification procedure for euthanasia). Utrecht: de Tijdstroom; 2003.

32. Statistics Netherlands; Central Death Registry 2001. Accessed at http: //statline.cbs.nl/StatWeb on 11 June 2004.
33. van der Heide A, Deliens L, Faisst K, Nilstun T, Norup M, Paci E, et al. End-of-life decision-making in six European countries: descriptive study. Lancet. 2003;362:345-50. [PMID: 12907005]

34. Cherny NI, Portenoy RK. Sedation in the management of refractory symptoms: guidelines for evaluation and treatment. J Palliat Care. 1994;10:31-8. [PMID: 8089815]

\section{Personae Photography Prize}

Annals of Internal Medicine is offering a $\$ 500$ prize for the best photograph submitted to Annals in 2004. In an effort to bring people to the pages of the Annals, the editors began publishing a section called Personae in 1999. Personae photographs are black and white photographs of people that appeared in the body of the journal from 1999 to 2000 and have appeared on the cover since 2000. Photographs submitted between 1 January 2004 and 31 December 2004 will be eligible for the prize. Employees of the American College of Physicians and their family members are not eligible for the prize but are welcome to submit photographs to be considered for publication.

We are looking for photographs that catch people in the context of their lives and that capture personality. Annals will publish photographs in black and white, and black-and-white submissions are preferred. The quality of photos and their suitability for the vertical space on the cover weigh heavily in publication decisions. We will also accept color submissions, but any publication decision will depend on the quality of the photograph after conversion to black and white. We prefer print submissions, but will accept slides or digital files. However, photographers may ultimately need to supply prints of photographs accepted for publication. Photographers should submit two copies of each print submission. We will not be able to return photographs, regardless of publication decision. Photographers should not submit their only copies of photographs.

We must receive written permission to publish the photograph from the subject (or subjects) of the photograph or the subject's guardian or next of kin. Occasionally, we can publish a photograph without the subject's permission under the following circumstances: 1) the subject is unidentifiable in the photograph, or 2) the photograph was taken in a public venue, is not potentially damaging to the subject, and is accompanied by a written statement from the photographer assuring that the photograph was taken in a public venue with the subject's consent. A cover letter assuring no prior publication of the photograph and providing permission from the photographer for Annals to publish the image should accompany all submissions. The letter should also contain the photographer's name, academic degrees, institutional affiliation, mailing address, and telephone and fax numbers. Photographers must sign over copyright permission to the American College of Physicians before publication. Photographers who do not find copyright assignment acceptable should refrain from submitting photographs for consideration.

Please submit photographs or questions to Christine Laine, MD, MPH, Senior Deputy Editor, Annals of Internal Medicine, $190 \mathrm{~N}$. Independence Mall West, Philadelphia, PA 19106-1572, claine@acponline.org. We look forward to receiving your photographs. 
Current Author Addresses: Drs. Rietjens, van der Heide, Vrakking, and van der Maas: Department of Public Health, Erasmus MC, PO Box 1738, 3000 DR Rotterdam, the Netherlands.

Drs. Onwuteaka-Philipsen and van der Wal: Department of Social Medicine, Vrije Universiteit Medical Center, van der Boechorststraat 7, 1081 BT Amsterdam, the Netherlands.

Author Contributions: Conception and design: J.A.C. Rietjens, A. van der Heide, A.M. Vrakking, B.D. Onwuteaka-Philipsen, P.J. van der Maas, G. van der Wal.

Analysis and interpretation of the data: J.A.C. Rietjens, A. van der Heide, A.M. Vrakking, B.D. Onwuteaka-Philipsen, P.J. van der Maas, G. van der Wal.
Drafting of the article: J.A.C. Rietjens, A. van der Heide.

Critical revision of the article for important intellectual content: J.A.C. Rietjens, A. van der Heide, A.M. Vrakking, B.D. Onwuteaka-Philipsen, P.J. van der Maas, G. van der Wal.

Final approval of the article: J.A.C. Rietjens, A. van der Heide, A.M. Vrakking, B.D. Onwuteaka-Philipsen, P.J. van der Maas, G. van der Wal.

Statistical expertise: J.A.C. Rietjens, A. van der Heide.

Obtaining of funding: A. van der Heide, B.D. Onwuteaka-Philipsen, P.J. van der Maas, G. van der Wal.

Administrative, technical, or logistic support: J.A.C. Rietjens.

Collection and assembly of data: J.A.C. Rietjens. 
Appendix Figure. Terminal sedation: frequencies and case characteristics.

\section{Questionnaire F: Terminal Sedation: Frequencies and Case Characteristics}

\section{Introduction}

In some cases, patients are deeply sedated or are put into an induced coma prior to death with the help of medications such as benzodiazepines or barbiturates. This may or may not include forgoing nutrition and/or hydration.

F1a Have you ever sought to alleviate pain or other symptoms in a terminally ill patient by deep sedation or by putting him or her into coma?

F1b When was the last time you did so?

Be as precise as possible

If before 1-1-2000 $\rightarrow$ go to question F2a

F1c In how many patients did you do so in 2001?

i.e. between 1-1-2001 and 31-12-2001

F1d In how many patients did you do so in $\underline{2000}$ ?

i.e. between 1-1-2000 and 31-12-2000

F2a Are there conceivable situations in which you would apply deep sedation to a patient prior to his or her death?

F2b Can you describe such a situation?
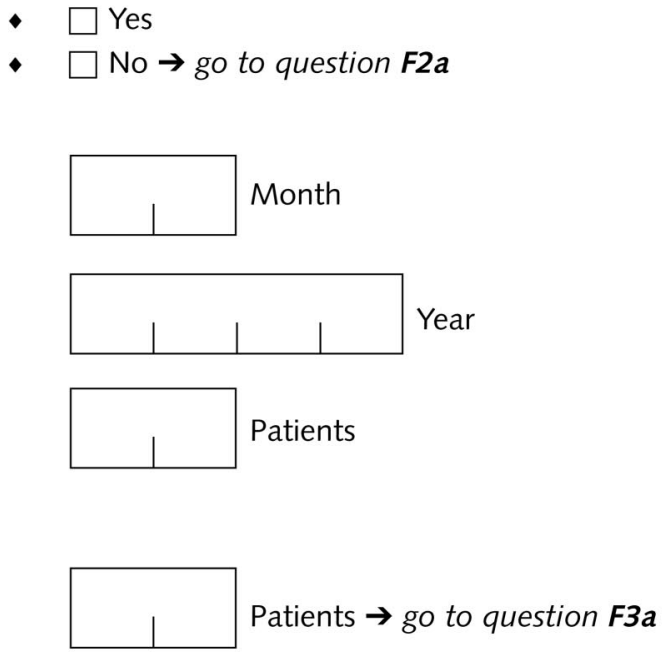

- $\square$ Yes

- $\square$ No $\rightarrow$ go to question F2c

$\rightarrow$ go to questionnaire $\boldsymbol{G}$

F2c Why not?

$\rightarrow$ go to questionnaire $G$

Throughout the questionnaire, phrases indicate that the respondent should be allowed to look at a particular card. Some questions include the use of cards with the possible answers for a particular question. The respondent can read the possible answers from the card and then choose the corresponding answer. ALS = amyotrophic lateral sclerosis; COPD = chronic obstructive pulmonary disease; CVD = cardiovascular disease; MS = multiple sclerosis. 
F3a Have you ever made the decision to forgo nutrition and/or hydration in a deeply sedated patient *?

* Note: no hydration and/or nutrition or only in severely limited quantities, i.e., not enough to sustain life.

F3b When did you last do so?

Be as precise as possible

If before 1-1-2000 $\rightarrow$ go to question F5

F3c In how many patients did you do so in 2001?

i.e. between 1-1-2001 and 31-12-2001

F3d In how many patients did you do so in $\underline{2000}$ ?

i.e. between 1-1-2000 and 31-12-2000

$\rightarrow$ go to question F5

F4a Are there conceivable situations in which you would forgo nutrition and/or hydration in a deeply sedated patient *?

* Note: no hydration and/or nutrition or only in severely limited quantities, i.e., not enough to sustain life

F4b Can you describe such a situation?
- $\square$ Yes

- $\square$ No $\rightarrow$ go to question F4a
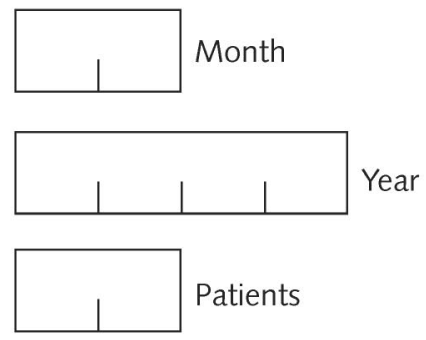

- $\square$ Yes

- $\square$ No $\rightarrow$ go to question F4c

$\rightarrow$ go to questionnaire $G$

F4c Why not?

$\rightarrow$ go to questionnaire $G$ 


\section{Questionnaire F: Terminal sedation, Case}

\section{Introduction}

I would now like to ask you a number of questions about the last time (regardless of when this happened) you practiced deep sedation on a patient prior to death while forgoing artificial nutrition and/or hydration, or giving artificial nutrition and/or hydration in quantities that were not sufficient as to sustain life.

I would like to start with a few questions about the patient

F5 Can you give a very brief description of the case?

This question is designed to have the respondent provide a summary introduction of the case and to establish whether this was indeed a case in which a patient was deeply sedated prior to death, to whom no or only very limited quantities of nutrition or hydration were administered.

F6 What was the main diagnosis?

- $\square$ Lung cancer

- $\square$ Colon cancer

- $\square$ Prostate cancer

- $\square$ Stomach cancer

- $\square$ Breast cancer

- $\square$ Pancreas cancer

- $\square$ Cancer, other, namely:

- $\square$ AIDS

- $\square$ CVD

- $\square$ Heart failure

- $\square$ MS

- $\square$ ALS

- $\square$ COPD

- $\square$ Old age/general deterioration

- $\square$ Other, namely: 
F7 Approximately how long had this patient been registered in your practice?

Mention possible answer categories
- $\square<1$ month

- $\square 1-3$ months

- $\square$ 4-6 months

$-\square 7-12$ months

- $\square 1-5$ years

- $\square>5$ years

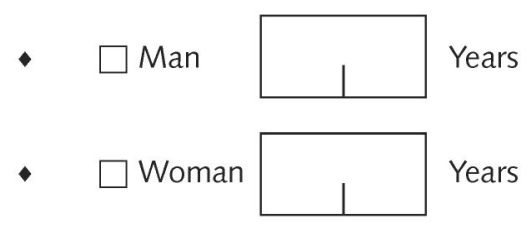

I would now like to ask you a number of questions about the treatment of the patient at the time of the decision making about deep sedation.

F9a What was the aim of the treatment at that moment?

Tick one or more answers

Mention possible answer categories

F9b Were there at that moment any realistic curative or life-prolonging treatment options available?

F9c Why did the patient not receive this/these treatment options?

Tick one or more answers
Cure

Prolonging life

Palliation (namely not aimed at prolonging life)

$\square$ Other, namely:

\begin{tabular}{|l|l|}
\hline \\
\hline
\end{tabular}

- $\square$ Yes

- $\square$ No $\rightarrow$ go to question F10a

Patient did not want to

Too little chance of improvement

Severity of expected side effects

Treatment was too much of a burden

Other, namely: 
Let the respondent look at card F1

F10a Can you indicate, on a 5-point scale, the extent to which the following signs or symptoms (in spite of any treatment) were present in this patient at the time of the decision making about deep sedation?

$\begin{array}{rllllll}\text { No pain } & 1 & 2 & 3 & 4 & 5 & \\ \text { No decubitus } & \square & \square & \square & \square & \square & \text { Severe pain } \\ \text { No obstipation } & \square & \square & \square & \square & \square & \text { Severe obstipation } \\ \text { Not nauseous } & \square & \square & \square & \square & \square & \text { Very nauseous } \\ \text { Not coughing } & \square & \square & \square & \square & \square & \text { Coughing a lot } \\ \text { Not vomiting } & \square & \square & \square & \square & \square & \text { Vomiting a lot } \\ \text { Not depressed } & \square & \square & \square & \square & \square & \text { Very depressed } \\ \text { Not afraid } & \square & \square & \square & \square & \square & \text { Very afraid } \\ \text { Not tired } & \square & \square & \square & \square & \square & \text { Very tired } \\ \text { Not confused } & \square & \square & \square & \square & \square & \text { Very confused } \\ \text { Clearly conscious } & \square & \square & \square & \square & \square & \text { Not clearly conscious } \\ \text { Good appetite } & \square & \square & \square & \square & \square & \text { Very little appetite } \\ \text { Not short of breath } & \square & \square & \square & \square & \square & \text { Very short of breath } \\ \text { Very active } & \square & \square & \square & \square & \square & \text { Not active } \\ \text { Feeling well } & \square & \square & \square & \square & \square & \text { Feeling ill }\end{array}$

F10b Was the patient treated for pain?

No

Tick one or more answers

Yes, with oral morphine

Yes, with rectal morphine

Yes, with morphine injections

$\square$ Yes, with morphine (fentanyl) plasters

Yes, with a morphine pump

Yes, with medication other than morphine, namely:

F10c Was the patient treated at that time for nausea or vomiting?

- $\square$ No

- $\square$ Yes, with:

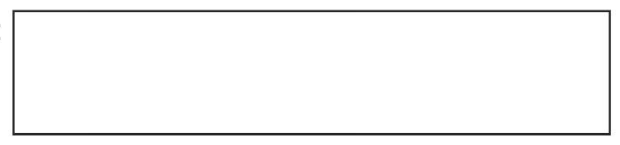

F10d Was the patient treated at that time for dyspnea?

- $\square$ No

- $\square$ Yes, with: 
F10e Was the patient treated at that time for depression?

F10f Was the patient treated at that time for confusion?

F10g Was the patient treated at that time to relieve other complaints or symptoms?

F11a What was the reason for deeply sedating the patient?

Tick one or more answers

F11b To what extent, in your opinion, was the suffering of the patient unbearable at the time of the decision making about the deep sedation?

Mention possible answer categories

F11c To what extent, in your opinion, was the suffering of the patient hopeless at the time of the decision making about the deep sedation?

Mention possible answer categories

F12a Did the patient regain consciousness at any time following the initiation of deep sedation?
- $\square$ No

- $\square$ Yes, with

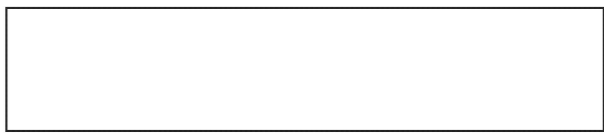

$-\square$ No

- $\square$ Yes, with

- $\square$ No

- $\square$ Yes, with

Pain

Agitation

Dyspnea

Other symptoms, namely:

- $\square$ To a great extent

- $\square$ To a certain extent

- $\square$ To a lesser extent

- $\square$ To a great extent

- $\square$ To a certain extent

- $\square$ To a lesser extent

- $\square$ Yes

- $\square$ No $\rightarrow$ go to question F13a 
F12b What was the reason for or cause of this?

Tick one or more answers

F13a In making the decision to apply deep sedation, was the possibility or the certainty that this could hasten death taken into account?

F13b Was sedation administered:

Let respondent now look at card F2

F13c What do you mean by "partially with the intention"?

Tick one or more answers
Dosage provided insufficient sedation

$\square$ For consultation about further decision making

Possibility of contact with family/relatives

To administer nutrition and/or hydration

Other, namely:

(2)

- $\square$ Yes

$\downarrow \quad \square$ No $\rightarrow$ go to question F14a

- $\square$ Without the intention to hasten death $\rightarrow$ go to question F14a

- $\square$ Partially with the intention of hastening death

$\rightarrow$ go to question F13C

- $\square$ With the explicit intention to hasten death

$\rightarrow$ go to question F14a

There was a more important intention, namely:

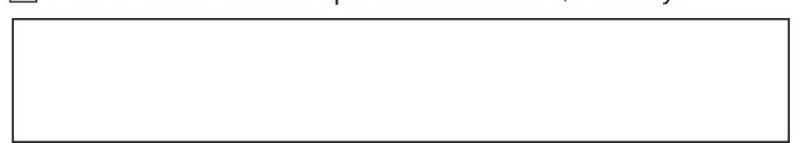

I accepted the additional effect of hastening death, but it was not my intention

My intention was also to hasten death

$\square$ Other, namely: 
I now want to ask a few questions about the medication that was used for the sedation

Let respondent look at card $\mathbf{F 3}$

F14a Which medication was given to bring the patient in deep sedation? (in sequence of administration):

F14b Name of the medication

F14c Method of administration Oral

Rectal

Intravenous

Other

F14d Amount in the final 24 hours
Medication 1
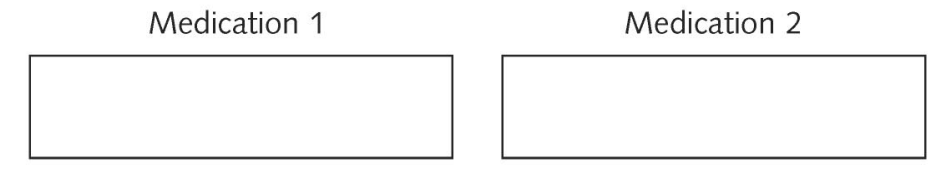

Medication 2
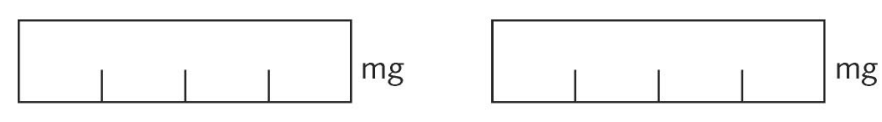

The following questions concern the nutrition and hydration policy

Let respondent now look at card F4

F15a Was the decision to forgo nutrition and/or hydration, or to administer this in only very limited quantities taken:

F15b What do you mean by "partially with the intention"?

Tick one or more answers
- $\square$ Without intending to hasten the end of life * $\rightarrow$ go to question F16a

- $\square$ Partially with the intention of hastening the end of life ${ }^{*} \rightarrow$ go to question F15b

- $\square$ With the explicit intention to hasten the end of life ${ }^{*} \rightarrow$ go to question F16a

* Note: "to hasten the end of life" or "not to prolong life"

There was a more important intention, namely:

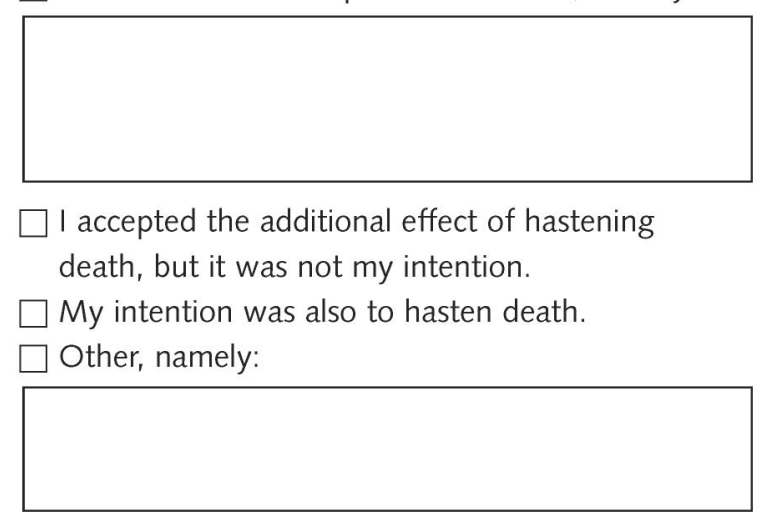


F16a Did the patient forgo or receive limited quantities of hydration and/or nutrition throughout the period of deep sedation prior to death?

Tick one or more answers

F16b With what intention were limited amounts of nutrition and/or hydration administered?

Tick one or more answers

F16c How long after the initiation of the (final period of) continuous deep sedation was it decided to forgo or to administer only limited amounts of nutrition and/or hydration?
Limited nutrition $\rightarrow$ go to question $\mathbf{F 1 6 b}$

Limited hydration $\rightarrow$ go to question $\mathbf{F 1 6 b}$

$\square$ No nutrition, no hydration $\rightarrow$ go to question $F 16 \mathrm{c}$

Compliance with the request of family or relatives

Reassurance of family or relatives

Compliance with a request from nursing staff

The patient's comfort

Alleviation of symptoms, namely:

Precautionary IV line

Other, namely:

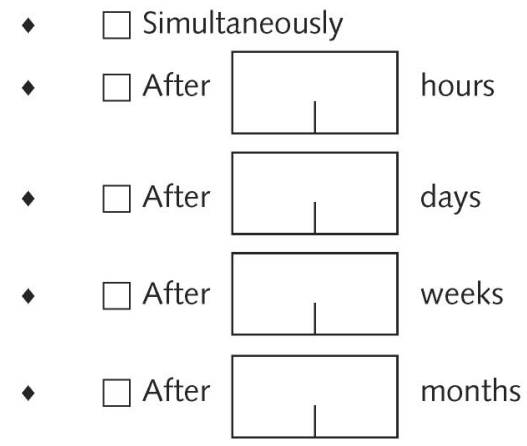

I would now like to ask you a number of questions about your decision-making process. First about the deep sedation and subsequently about the forgoing of nutrition and/or hydration.

F17a Did you, or another physician, discuss the decision to apply deep sedation with the patient?
- $\square$ Yes $\rightarrow$ go to question F17c

$\checkmark \quad \square$ No 
F17b Why did you not discuss this with the patient?

Tick one or more answers

F17c Did the patient request deep sedation?

Let respondent now look at card F5

F17d What were the most important reasons for the patient to make his or her request?

Tick one or more answers
Patient was not (no longer) fully lucid

$\square$ Patient was too young

$\square$ Patient suffered from dementia

$\square$ Patient was mentally disabled

$\square$ Patient had a psychiatric disorder

Patient was subcomatose

The proposed course of action was clearly the best for the patient

$\square$ Discussion would do the patient more harm than good

Other, namely:

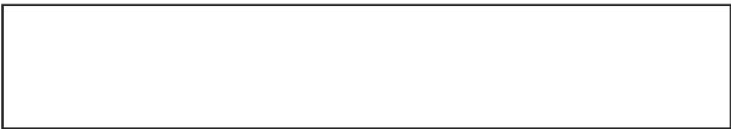

$\rightarrow$ go to question F18a

- $\square$ Yes

- $\square$ No $\rightarrow$ go to question F18a

$\square$ Pain

$\square$ Dyspnea

Other symptoms, namely:

$\square$ Humiliation/loss of self-esteem

$\square$ General weakness/fatigue

Tired of life

$\square$ No reason to suffer anymore

$\square$ Suffering with no hope of improvement

$\square$ Vomiting

Fear of suffocating

$\square$ Invalidity/immobility

Depression

Dependence

$\square$ Not (or no longer) wanting to be a burden on family/environment

Other, namely: 
F18a Did you discuss the sedation with other caregivers?

Let respondent now look at card F6

F18b Who were the caregivers with whom you discussed?

Tick one or more answers
- $\square$ Yes

- $\square$ No $\rightarrow$ go to question F18c

Colleague physician in my own field

Colleague physician in a different field, namely:

Nursing staff

Specialists in palliative care from other institutions

Pain Management Team

$\square$ Other, namely:

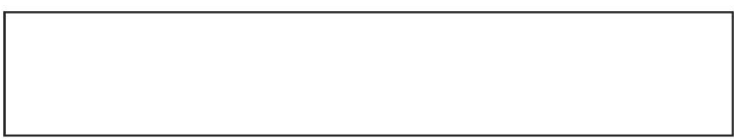

- $\square$ Yes

- $\square$ No $\rightarrow$ go to question F19a

- $\square$ Yes

- $\square$ No

- $\square$ Yes $\rightarrow$ go to question F19c

- $\square$ No decision to forgo, or to administer only limited amounts of nutrition and/or hydration, with the patient?

F19b Why did you not discuss this with the patient?

$\rightarrow$ go to question F20a

F19c Did the patient request to forgo nutrition and/or hydration?

- $\square$ Yes

- $\square$ No $\rightarrow$ go to question F20a 
F19d What was the reason for the patient's request?

F20a Did you discuss with other caregivers whether or not to forgo nutrition and/or hydration?

F20b Who were the caregivers with whom you discussed?

Tick one or more answers $-\square$ Yes
- $\square$ No $\rightarrow$ go to question F20c

Colleague physician in my field

Colleague physician in a different field, namely:

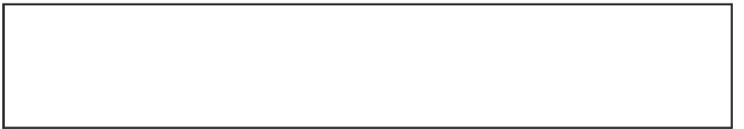

Nursing staff

Specialists in palliative care from other institutions

Pain Management Team

Other, namely:

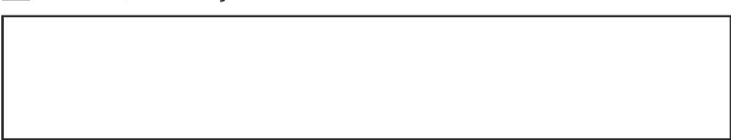

- $\square$ Yes

- $\square$ No $\rightarrow$ go to question F21a

- $\square$ Yes

- $\square$ No

- $\square$ Yes

- $\square$ No $\rightarrow$ go to question F22 been a subject of discussion with this patient?

F21b Why was euthanasia or assisted suicide not performed? 
F22a How long after the initiation of (the final period of) continuous deep sedation did the patient die?

F22b In your opinion, by how much time was the patient's life shortened by the combination of deep sedation and the forgoing, or administration of very limited quantities, of nutrition and/or hydration?

Mention possible answer categories

F23 Reviewing the situation as a whole, how do you think your actions affected the quality of the patient's end of life?

Tick one or more answers

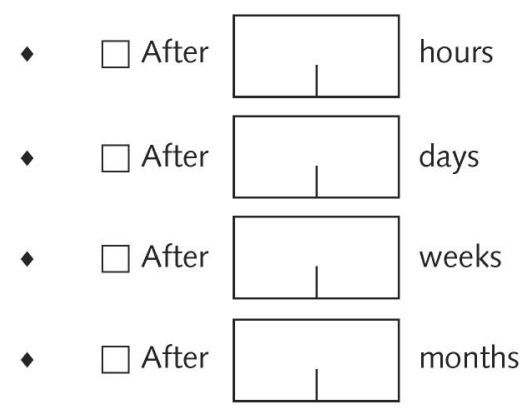

- $\square$ More than half a year

- $\square$ One to six months

- $\square$ One to four weeks

- $\square$ A week, at the maximum

- $\square$ Less than 24 hours

- $\square$ Probably did not have any life-shortening effect

Improved end-of-life quality

Had little effect

Don't know, haven't thought about it

Don't know, hard to assess

Other, namely: 